Cut" corn meal, an approximately 2-gram sample being used in the extractions:

\begin{tabular}{|c|c|c|c|c|c|c|}
\hline & & & & Perc & centages. & \\
\hline & Car & bor te & trachlo & ride. & Petroleum & \\
\hline & Dry sa & mple. & $\begin{array}{l}\text { Wet s } \\
\text { (Cal. } 0\end{array}$ & $\begin{array}{l}\text { ample. } \\
\text { n dry.) }\end{array}$ & $\begin{array}{l}16 \text { hours' } \\
\text { extraction. }\end{array}$ & $\begin{array}{l}16 \text { hours' } \\
\text { extraction. }\end{array}$ \\
\hline 1st blow-off. & 2.91 & 2.93 & 3.03 & 3.02 & & \\
\hline nd blow-off...... & 0.24 & 0.36 & 0.17 & 0.28 & & \\
\hline 3rd blow-off....... & 0.05 & 0.00 & 0.07 & 0.00 & & \\
\hline Total & $1,3.20$ & 3.29 & 3.27 & 3.30 & 3.21 & 3.23 \\
\hline
\end{tabular}

On millet flour from Crookston, Minn., containing 7 per cent. of moisture.

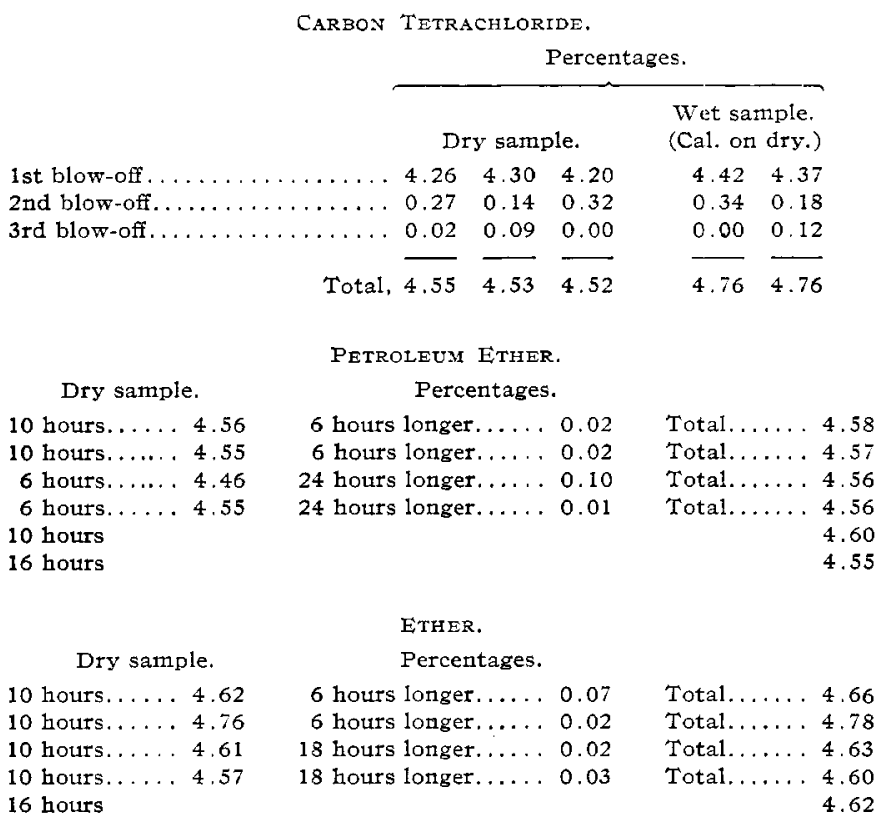

On wheat germ from the Washburn Crosby Milling Co., Minneapolis.

Carbon Tetrachloride.

Percentages.

Wet sample, Different sample, No. 2 No. 1 . (Cal. on dry.) Wet sample.

Dry sample. No. 1. Av, of 7 . Dry sample. (Cal. on dry.)

$\begin{array}{rrrrrr}\text { 1st blow-off . . . } 10.15 & 10.14 & 10.23 & 11.77 & 11.78 \\ \text { 2nd blow-off..... } & 0.51 & 0.54 & 0.47 & 11.90 & 11.90 \\ \text { 3rd blow-off..... } 0.15 & 0.17 & 0.11 & 11.78 & 11.77 \\ \text { 4th blow-off..... } & 0.02 & 0.01 & 0.02 & & 11.87 \\ \text { Total, } 10.83 & \overline{10.86} & \overline{10.83} & & \end{array}$

Petroletim Ether.

$$
\text { Sample No, 1. Percentages. }
$$

5 hours $10.78 \quad 5$ hours longer 0.15

5 hours 10.745 hours longer 0.20

5 hours 10.745 hours longer 0.125 hours longer $0.0 \bar{i}$ Total 10.93

6 hours

6 hours

10 hours

10 hours

10 hours

16 hours

16 hours

16 hours

16 hours

16 hours
ETHER.

Sample No. 1. Percentages.

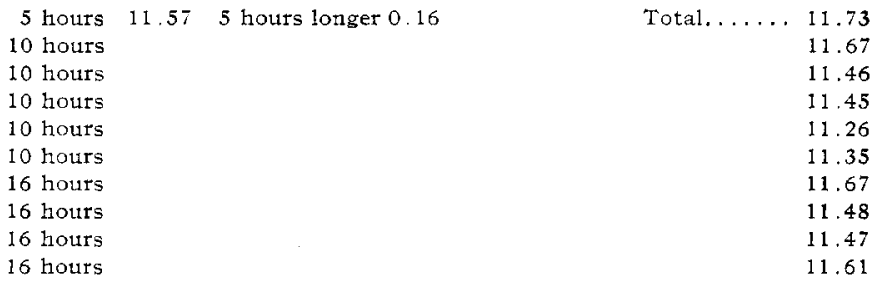

The above method for the determination of oil in grains gives very satisfactory results compared with those obtained by means of petroleum ether and ether as solvents.

(I) It is a short method, two and one-half hours being required for a complete determination.

(2) There is no difficulty encountered in removing the last trace of the solvent.

(3) The oil extracted is purer than that extracted by petroleum ether or ethyl ether, as shown by a higher iodine absorption value.

(4) It is a rapid control method.

Chemical Laboratory,

University of Minnesota, MINNEAPOLIS.

\section{SOY BEAN CHEESE. ${ }^{1}$}

BY WILITAM V. LINDER.

Received Aug. 22, 1912.

In the line of my official work a few weeks ago, I had occasion to examine two samples sent to the laboratory from a western state; these were suspected of being filled cheese. Cheese made from cream, or milk containing fat other than that derived from the cream or milk used in its production, is classed as filled cheese and subject to an internal revenue tax of one-quarter of a cent per pound.

The samples somewhat resembled in appearance and taste a very soft and mushy cream cheese, saturated with water.

On account of the difficulty of obtaining a true sample, due to the large amount of water present, it was decided to make an analysis on a moisture-free basis only. About roo grams were dried in an electric oven and the analysis made on the dry sample, with the following results:

$\begin{array}{ccccc}\text { Laboratory No. } & \begin{array}{r}\text { Protein. } \\ \text { Per cent. }\end{array} & \begin{array}{c}\text { Fat. } \\ \text { Per cent. }\end{array} & \begin{array}{c}\text { Ash. } \\ \text { Per cent. }\end{array} & \text { Sugar. } \\ 429991 \ldots \ldots \ldots \ldots \ldots & 39.31 & 7.80 & 2.36 & \text { None } \\ 43285 \ldots \ldots \ldots \ldots & 45.07 & 6.04 & 1.83 & \text { None }\end{array}$

One hundred grams of each sample were extracted with ether and the fat obtained examined, with the following results:

\begin{tabular}{|c|c|c|}
\hline Laboratory No. & $\begin{array}{l}\text { Index of refrac- } \\
\text { tion at } 25^{\circ} \mathrm{C} \text {. }\end{array}$ & Iadine No. \\
\hline $\begin{array}{l}42991 \ldots \\
43285 \ldots\end{array}$ & $\begin{array}{r}\ldots 1.4749 \\
\ldots \quad 1.4742\end{array}$ & $\begin{array}{l}130.4 \\
128.7\end{array}$ \\
\hline
\end{tabular}

From the results obtained it was clear that the fat could not have been derived from milk or cream and

1 Published by permission of the Commissioner of Internal Revenue. 
the failure to find milk sugar also indicated that no milk or cream had been used in their production.

The analysis of the fat indicated that it was soy bean oil, and as soy beans contain a large percentage of protein, it was at once suspected that this was one of the numerous products made from them. It is a well known fact that in China and Japan soy beans have been used for hundreds of years, not only to produce an edible oil, but in the production of many other food products.

Two hundred grams of soy bean meal, ground from the whole bean in the laboratory, were thoroughly mixed in $1000 \mathrm{cc}$. of cold water. After standing twelve hours fermentation set in and continued for three days. No effort was made to ascertain the nature of this fermentation. At the end of this time the mash, upon which a mold had started to grow, was strained through cheese cloth; a heavy, milky liquid was obtained. Numerous methods were tried to coagulate the suspended and dissolved protein, such as the addition of acids, rennet, and heat. Heating upon the steam bath seemed to give the most satisfactory results as the dissolved material coagulated and settled out upon standing.

The coagulated mass was filtered, giving a product that was identical in appearance, taste and odor with the two samples examined. The dried product was analyzed showing the similarity beyond any doubt.

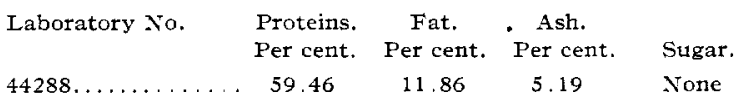

The investigation proved that the product submitted for examination could not be classed as filled cheese, although a very good substitute. Cheese prepared from soy beans must be consumed within a few days as it deteriorates very rapidly.

While making this investigation I confirmed the work of J. Ruhiah, ${ }^{\mathrm{I}}$ who found sucrose present in soy beans. The beans that I used contained 4.4 per cent. sucrose.

As thousands of tons of soy beans are used annually in making oil, it does not seem improbable that a method could be found which would make the recovery of the sucrose possible without reducing the yield or injuring the quality of the meal for feeding purposes. It would be a source of profit from an industrial product that is now entirely wasted.

LABORAtory BUREAU OF INTERNAI ReVENuE, WASHINGTON, D. C.

\section{LABORATORY AND PLANT}

\section{A NEW FORM OF ORSAT APPARATUS.}

By I. M. Dennis.

Received October 14, 1912.

In the analysis of commercial grades of sodium carbonate there early arose a demand for a rapid and convenient method for the determination of carbon dioxide, which was met in I 868 by the apparatus designed by Schlösing and Rolland. ${ }^{2}$ In 1874 Orsat patented a device ${ }^{2}$ that was based directly upon the principle of the apparatus of Schlösing and Rolland, and that attracted considerable attention at the time and rapidly came into general use. Because of its compactness and ease of manipulation, the Orsat apparatus has been and still is very generally employed by gas analysts. In its original form, however, and even in some of the later modifications, it possesses certain inherent faults, and the unsatisfactory character of the analytical results that are obtainable with the various forms is evidenced by the large number of changes in its construction that are constantly being brought forward in chemical journals. The chief objection to the apparatus is the incompleteness of the absorption of such gases as oxygen and carbon monoxide. The researches of Gautier and Clausmann, Bendemann, Hankus, Hempel, Nowicki, Hahn, Dennis and Edgar, and others, have demonstrated that the complete removal of oxygen by alkaline pyrogallol and of carbon monoxide by cuprous chloride can be effected only when the absorbent and the gas are

\footnotetext{
1 Annales de chimie et de physique, 4 serie, 14, 55 (1868).
}

2 Chem. Neics, 29, 176 (1874). shaken together, or when the gas is, in some manner, brought into prolonged and intimate contact with the absorbent. With most of the suggested forms of the Orsat absorption pipette, the removal of oxygen and carbon monoxide is quite incomplete unless the gas is allowed to stand in contact with the absorbent for a very considerable length of time, or is passed back and forth many times between the burette and pipette. Failure to recognize this inadequacy of the apparatus frequently results in the incomplete removal of oxygen, and, as a consequence, a decrease in volume is observed when the gas mixture is next passed. into the cuprous chloride pipette. In very many cases the analyst has, in this manner, been led into reporting carbon monoxide in a gas mixture, such as flue gas, when in fact no carbon monoxide is present, the decrease in volume being due solely to the absorption, by cuprous chloride, of oxygen that still remains in the gas mixture.

In recent years several interesting and some valuable suggestions for increasing the completeness and rapidity of absorption in the Orsat apparatus have appeared in chemical journals. Bendemann proposes ${ }^{2}$ that two pipettes be used for the absorption of oxygen by alkaline pyrogallol and two for the removal of carbon monoxide by cuprous chloride. This would undoubtedly lessen the errors of the determinations but would hardly remove them entirely. More worthy of consideration are the proposed modifications of the form of the absorption pipette to bring

I See Chemical Abstracts, 4, 1789, 1912,

2 J.f. Gasbeleuchtung, 49, 853 (1906). 